\title{
Allelic loss of 10q23, the PTEN tumour suppressor gene locus, in Barrett's oesophagus-associated adenocarcinoma
}

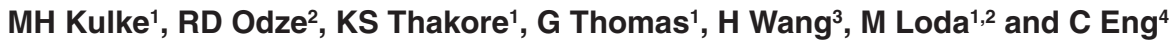 \\ 'Department of Adult Oncology, Dana-Farber Cancer Institute and Harvard Medical School, Boston MA; '2Department of Pathology, Brigham and Women's \\ Hospital, and Harvard Medical School, Boston MA; ${ }^{3}$ Department of Pathology, Beth-Israel-Deaconess Medical Center and Harvard Medical School, Boston MA; \\ ${ }^{4}$ Human Cancer Genetics Program, Ohio State University, Columbus, Ohio, and CRC Human Cancer Genetics Research Group, University of Cambridge, \\ Cambridge, UK
}

\begin{abstract}
Summary PTEN is a putative tumour suppressor gene located on chromosome band 10q23. Mutations in PTEN have been identified in numerous human malignancies, including cancers of the brain, endometrium, ovary, and prostate. In this study, we screened 80 Barrett's oesophagus-associated adenocarcinomas (BOAd) for loss of heterozygosity (LOH) at 10q23, using the microsatellite markers D10S541, D10S219, and D10S551. Tumours demonstrating LOH were then screened for the presence or absence of $P$ TEN mutations. LOH at one or more loci was identified in $17 / 80(21 \%)$ cases. In none of these cases did we detect mutations in PTEN. The presence of LOH did not correlate with patient age, tumour stage, degree of differentiation, presence of perineural or vascular invasion, or overall survival. We conclude that $\mathrm{LOH}$ at chromosome $10 \mathrm{q} 23$ is uncommon in BOAd, is not associated with mutations in the PTEN tumour suppressor gene, and does not correlate with the clinical or pathologic features of these tumours. It is possible that PTEN is inactivated through other mechanisms in BOAd. (C) 2001 Cancer Research Campaign http://www.bjcancer.com
\end{abstract}

Keywords: PTEN; Barrett's oesophagus; oesophageal adenocarcinoma; 10q23

In North America, the incidence of oesophageal adenocarcinoma is increasing at a rate higher than any other malignancy (Blot et al, 1991). The development of oesophageal adenocarcinoma is related to chronic gastro-oesophageal reflux and the subsequent development of Barrett's oesophagus (Lagergren et al, 1999). However, the molecular events leading to the development of oesophageal adenocarcinoma remain poorly understood.

Loss of tumour suppressor gene function may play a role in the development of oesophageal adenocarcinoma. Allelotype analysis of oesophageal adenocarcinoma specimens has revealed frequent loss of heterozygosity ( $\mathrm{LOH})$ at several sites of known tumour suppressor genes. These sites include 17p (p53), 18q (DCC); 9p21 (CDKN2/p16), and 5q (APC) (Huang et al, 1992; Hammoud et al, 1996; Dolan et al, 1998). PTEN has recently been identified as a novel tumour suppressor gene that is deleted or mutated in a wide range of human malignancies ( $\mathrm{Li}$ et al, 1997; Steck et al, 1997). PTEN is located on chromosome band 10q23, and encodes a 403 amino acid dual specificity phosphatase that contains regions of homology to tensin and auxillin, cytoskeletal proteins that interact with adhesion molecules (Myers et al, 1997). Germline mutations of PTEN have been found in Cowden syndrome, an autosomal dominant inherited cancer syndrome characterized by hamartomas

Received 17 July 2000

Revised 14 November 2000

Accepted 30 November 2000

Correspondence to: $\mathrm{MH}$ Kulke of the skin, intestine, breast and thyroid, and associated with a high risk of breast and thyroid cancers (Liaw et al, 1997). Germline mutations in PTEN have also been found in Bannayan-Zonana syndrome, which is characterized by intestinal hamartomatous polyps, lipomatosis, macrocephaly, and speckled penis, as well as in a Proteus-like syndrome (Marsh et al, 1997a, 1999; Zhou et al, 2000).

Somatic mutations of PTEN have been found in sporadic tumours of the breast (Teng et al, 1997; Chen et al, 1999; Freihoff et al, 1999), thyroid (Dahia et al, 1997), head and neck (Okami et al, 1998; Shao et al, 1998), central nervous system (Liu et al, 1997; Rasheed et al, 1997; Teng et al, 1997; Wang et al, 1997; Bostrom et al, 1998; Chiariello et al, 1998; Duerr et al, 1998; Maier et al, 1998; Davies et al, 1999; Zhou et al, 1999), endometrium (Kong et al, 1997; Risinger et al, 1997; Tashiro et al, 1997; Simpkins et al, 1998; Mutter et al, 2000; Yaginuma et al, 2000), ovary (Tashiro et al, 1997; Teng et al, 1997; Obata et al, 1998; Saito et al, 2000), prostate (Cairns et al, 1997; Dong et al, 1998; Gray et al, 1998; Pesche et al, 1998; Suzuki et al, 1998; Feilotter et al, 1999), kidney (Teng et al, 1997; Alimov et al, 1999), lung (Kohno et al, 1998; Yokomizo et al, 1998), and in melanomas (Teng et al, 1997; Tsao et al, 1998) and non-Hodgkins lymphomas (Gronbaek et al, 1998; Nakahara et al, 1998; Sakai et al, 1998; Butler et al, 1999; Dahia et al, 1999). Whether loss of $P T E N$ function plays a role in the development of Barrett's oesophagusassociated adenocarcinoma (BOAd) is not known. In this study, we determined the prevalence and clinical significance of $\mathrm{LOH}$ at $10 \mathrm{q} 23$ in 80 cases of BOAd. Tumours demonstrating $\mathrm{LOH}$ were screened for PTEN mutations to determine if PTEN inactivation plays a role in the development of this type of malignancy. 


\section{MATERIALS AND METHODS}

\section{Study group}

80 patients who had en bloc oesophageal resection at the Brigham and Women's Hospital and at the Beth Israel-Deaconess Hospital between 1973 and 1995 were identified. All patients had histologically confirmed BOAd, and none had received preoperative chemotherapy or radiation. All patients were treated surgically with an intent to cure.

Selected clinical information (patient age, gender) and followup data were obtained from review of the patient's hospital charts and the hospital tumour registry, or from direct telephone interviews with the patient and/or his/her family when necessary. Follow-up time was calculated from the date of initial diagnosis to either the date of death or, for the patients who were still alive, to the date of the most recent clinical investigation. In the survival analysis, either death or tumour recurrence was considered a failure (event). Patients alive without disease at last follow-up were censored in the analysis.

\section{Pathologic analysis}

All oesophageal resection specimens were received in the surgical pathology laboratory in the fresh state and fixed in $10 \%$ buffered formalin for subsequent tissue sectioning. Tissue sections were processed routinely, embedded in paraffin, and stained with haematoxylin and eosin ( $\mathrm{H} \& \mathrm{E})$.

The following microscopic features were evaluated in all cases by one of the authors (RDO): 1) Pathologic stage according to the 1993 revised AJCC TNM classification (Fleming et al, 1997); 2) The presence or absence of lymphovascular invasion; 3) The presence or absence of perineural invasion; 4) Degree of tumour differentiation (well, $>95 \%$ of the tumour composed of glands; moderate, $50-95 \%$ of the tumour composed of glands; poor, $<50 \%$ of the tumour composed of glands).

\section{Molecular analysis}

Sections from paraffin-embedded tumour specimens were cut. Tumour and normal tissue were identified and separated by microdissection. DNA extraction was performed using the QIAprep kit (Qiagen Inc, Chatsworth, CA). PCR amplification was performed using primers for 3 known microsatellite repeat sequences: D10S219, D10S541, and D10S551. PCR primers were 5 ' tagged with fluorescent dye labels. PCR products were then electrophoresed on $6 \%$ denaturing polyacrylamide gels and results were analysed using GeneScan 672 collection and analysis software (Genescan, Applied Biosystems, Foster City CA). Loss of one PTEN allele was established when the normal:tumour DNA peak ratio was greater than 1.5:1.

All cases demonstrating $\mathrm{LOH}$ were analysed further with denaturing-gradient gel electrophoresis (DGGE). In these cases, DGGE was completed for all nine exons of PTEN. GC-clamped primers for each exon have been previously described (Guldberg et al, 1997; Marsh et al, 1997a, 1998). PCR products were generated using the following conditions: a 'hot start' at $95^{\circ} \mathrm{C}$ for $10 \mathrm{~min}$; followed by 40 cycles of $94^{\circ} \mathrm{C}$ for $1 \mathrm{~min}$, annealing at $55^{\circ} \mathrm{C}$ for $1 \mathrm{~min}$, and extension at $72^{\circ} \mathrm{C}$ for $1 \mathrm{~min}$; followed by $72^{\circ} \mathrm{C}$ for $10 \mathrm{~min}$. Heteroduplexing of PCR products was performed with one cycle of $98^{\circ} \mathrm{C}$ for $8 \mathrm{~min}, 55^{\circ} \mathrm{C}$ for $30 \mathrm{~min}$, and $40^{\circ} \mathrm{C}$ for 30 min. PCR was performed in 1X PCR buffer (Life Technologies
Inc.) $0.4 \mu \mathrm{M}$ primer (Life Technologies, Inc. and 2.5 units of Taq polymerase (Life Technologies, Inc) with TaqStart antibody (Clontech, Palo Alto, CA). PCR products were separated on $1 \mathrm{~mm}$ $10 \%$ polyacrylamide gels with a gradient of $15-20 \%$ urea and $0-10 \%$ glycerol. Gels were run at $100 \mathrm{~V}$ for $16 \mathrm{~h}$ at $60^{\circ} \mathrm{C}$.

Cases in which the DGGE analysis was not definitive were sequenced directly. In these cases, the exon in question was sequenced using nested primers designed within the flanking intronic sequences. PCR conditions and primers for sequencing have been previously described (Liaw et al, 1997; Marsh et al, 1997b; Steck et al, 1997).

\section{Statistical analysis}

The data analysis was done with STATA statistical software (STATA Corporation, College Station, Texas). Comparison of categorical data was done with either chi-square or Fisher's exact test, depending on sample size. Comparison for numeric data was done with the $t$-test. Survival analysis for clinical and pathologic variables was performed using a log-rank test. All variables that were statistically significant by univariate analysis $(P<0.05)$ were also evaluated by multivariate analysis. Kaplan-Meier curves were determined for selected groups of patients for comparison of survival.

\section{RESULTS}

A total of 80 BOAd specimens were analysed. Of the 80 samples, 63 had pathologic and clinical follow-up data. The demographic and pathologic features of the patients are summarized in Table 1. Patients had a mean age of 62 years and were predominantly male $(\mathrm{M}: \mathrm{F}=8: 1)$. The mean follow-up time was 33 months. At the time of last evaluation, $22(35 \%)$ were alive and disease-free, $1(2 \%)$ was alive with disease, and $39(62 \%)$ had died of disease. All stages of disease were represented in the group: $12(19 \%)$ patients had stage I, 14 (22\%) stage IIA, 9 (14\%) stage IIB, 24 (38\%) stage III, and $4(6 \%)$ stage IV lesions.

Table 1 Demographic and pathologic features of the patient population

\begin{tabular}{llrc}
\hline Characteristic & \multicolumn{3}{c}{ No. of patients } \\
\hline Number of patients & & 63 & \\
Mean age (years) & & 62 & $(37-87)$ \\
Male:female ratio & & $8: 1$ & $(56: 7)$ \\
Follow-up (months) & & $(1-204)$ \\
Survival status & & \\
& Alive without disease & 22 & $(35 \%)$ \\
& Alive with disease & 1 & $(2 \%)$ \\
& Dead of disease & 39 & $(62 \%)$ \\
& Dead of other causes & 1 & $(2 \%)$ \\
Pathologic stage & & & \\
& I & 12 & $(19 \%)$ \\
& IIA & 14 & $(22 \%)$ \\
& IIB & 9 & $(14 \%)$ \\
& III & 24 & $(38 \%)$ \\
Tumour differentiation & IV & 4 & $(6 \%)$ \\
& Well-differentiated & 4 & $(7 \%)$ \\
& Moderately differentiated & 32 & $(55 \%)$ \\
& Poorly differentiated & 22 & $(38 \%)$ \\
Perineural invasion & & 16 & $(25 \%)$ \\
Vascular invasion & & 25 & $(40 \%)$ \\
\hline
\end{tabular}


80 samples were analysed for evidence of LOH at 10q23. A panel of loci was initially evaluated in DNA extracted from the paraffin-embedded samples. We found that several of these markers, including AFMa086, a polymorphic marker within the PTEN gene, did not yield reproducible results in the archival specimens. 3 microsatellite loci (D10S219, D10S541 and D10S551) were selected for further study based on their reproducibility in our specimens and on their location flanking the PTEN tumour suppressor gene (Figure 1). Of the 3 markers, D10S541 is telomeric and in closest proximity to PTEN $(<0.3 \mathrm{cM})$ whereas D10S219 and D10S551 are centromeric and more distant from the gene ( $9 \mathrm{cM}$ and $6 \mathrm{cM}$, respectively). A representative example of $\mathrm{LOH}$ is shown in Figure 2. All but one case were evaluable for LOH with at least one microsatellite marker (Figure 3). LOH was found most commonly at the D10S541 locus $(11 / 70 ; 15.7 \%)$ and less commonly at D10S219 (4/74; 5.4\%) and D10S551 (4/76; $5.2 \%)$. In almost all cases, $\mathrm{LOH}$ was found at only one of 3 loci examined. In 2 cases, LOH was noted at 2 loci. The first (\#31) demonstrated LOH at both D10S219 and D10S551, and the second (\#55) demonstrated LOH at D10S219 and D10S541. In no cases did all 3 loci demonstrate $\mathrm{LOH}$. The total prevalence of $\mathrm{LOH}$ at one or more loci was $17 / 80(21 \%)$.

DGGE was performed on all cases demonstrating $\mathrm{LOH}$ to determine if PTEN mutations were present in the remaining allele. All 9 exons of PTEN were analysed. In all but 9 cases, DGGE analysis demonstrated no evidence of PTEN mutations. In these 9 cases, the results of DGGE were not interpretable, and direct sequencing of the PTEN exon in question was performed. In none of these cases were mutations in PTEN found.

No relationship was found between the presence of $\mathrm{LOH}$ at 10q23 and patient age $(P=0.98)$, degree of tumour differentiation $(P=0.58)$, tumour stage $(P=0.43)$, presence of perineural invasion $(P=0.32)$, or the presence of vascular invasion $(P=$ $0.37)$. There was no correlation between the presence of $\mathrm{LOH}$ and overall survival $(P=0.63)$.

\section{DIscussion}

An analysis of 80 cases of BOAd demonstrated LOH at chromosome $10 \mathrm{q} 23$ in $21 \%$ of cases. $\mathrm{LOH}$ was found most commonly with the microsatellite locus D10S541, which is only several hundred $\mathrm{Kb}$ from $P T E N$, and less commonly at the microsatellite

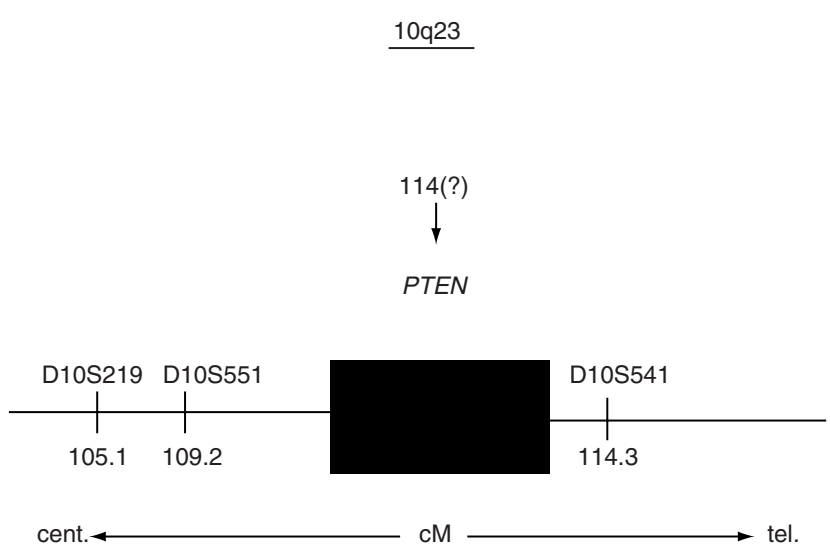

Figure 1 Location of the microsatellite loci D10S219, D10S551, and D10S541 in relation to PTEN

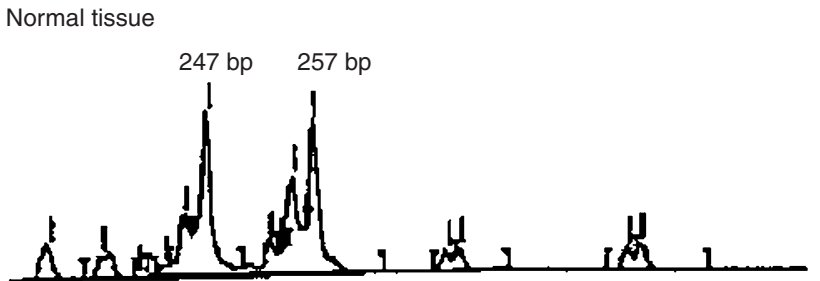

Tumour tissue

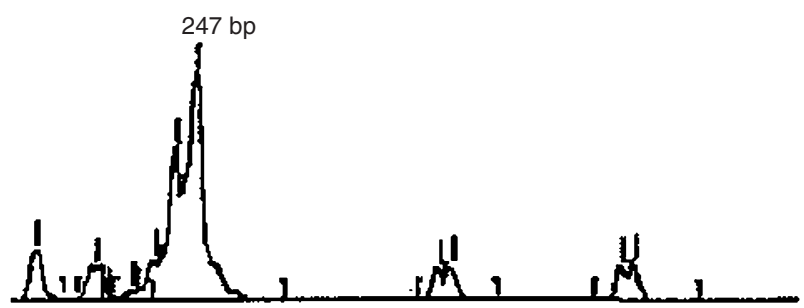

Figure 2 Representative Genescan analysis demonstrating $\mathrm{LOH}$ at D10S541. Normal tissue demonstrates presence of two alleles, 247 and $257 \mathrm{bp}$ in size. Tumour tissue demonstrates loss of the $257 \mathrm{bp}$ allele

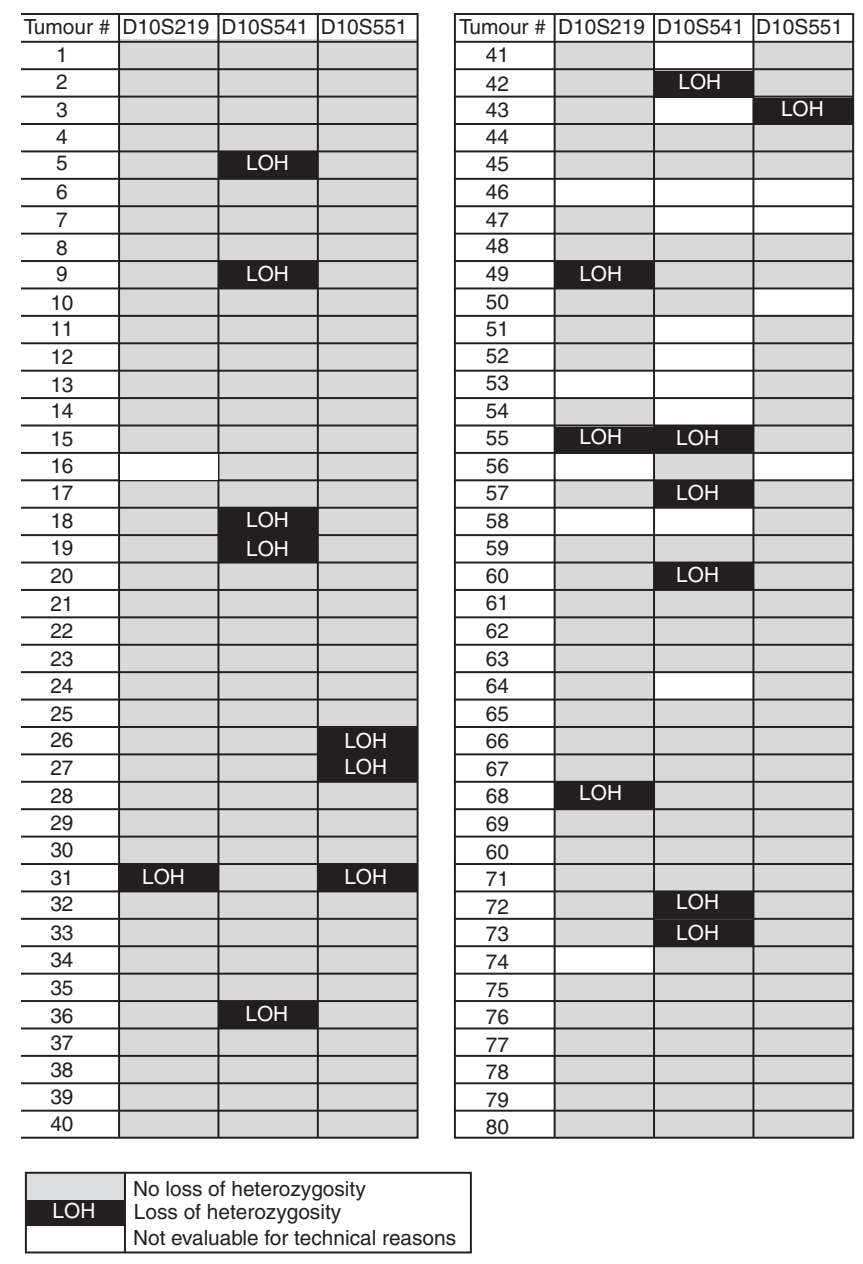

Figure $3 \mathrm{LOH}$ analysis of oesophageal cancer specimens 
markers D10S219 and D10S551, which are more distant from the PTEN locus. Studies of the $10 \mathrm{q} 23$ region in other malignancies have also noted a higher rate of LOH at the D10S541 locus, leading to speculation that loss of this marker correlates closely with loss of PTEN. In an analysis of sporadic breast cancers using 11 microsatellite markers, LOH at D10S541 was found more commonly than with any other marker, and occurred in $55 \%$ of cases (Singh et al, 1998a).

To assess if biallelic structural defects of PTEN play a role in the development of oesophageal adenocarcinoma, we screened all 17 cases that demonstrated LOH for PTEN mutations using DGGE and, when necessary, direct sequence analysis. In no case did we find evidence of PTEN mutations in the respective remaining allele. The finding of 10q23 LOH without associated PTEN mutations is not unprecedented. Both 10q23 LOH and somatic PTEN mutations have been demonstrated in endometrial carcinomas (Kong et al, 1997; Mutter et al, 2000), endometrioid ovarian carcinoma (Teng et al, 1997; Obata et al, 1998; Saito et al, 2000), and high-grade gliomas (Teng et al, 1997; Wang et al, 1997; Bostrom et al, 1998; Chiariello et al, 1998; Zhou et al, 1999). However, despite the presence of 10q23 LOH, somatic mutations of PTEN are either absent or exceedingly rare in primary cancers of the pancreas (Okami et al, 1998), kidney (Teng et al, 1997; Alimov et al, 1999), bladder (Cairns et al, 1998; Aveyard et al, 1999), prostate (Cairns et al, 1997; Feilotter et al, 1998; Pesche et al, 1998; Suzuki et al, 1998), breast (Feilotter et al, 1999; Freihoff et al, 1999), thyroid (Dahia et al, 1997), head and neck (Shao et al, 1998; Gasparotto et al, 1999; Okami et al, 1998), and lung (Okami et al, 1998; Petersen et al, 1998).

Several investigators have suggested that the lack of PTEN mutations in these malignancies can be explained by the presence of another tumour suppressor gene located at 10q23 (Bostrom et al, 1998; Feilotter et al, 1998; Butler et al, 1999; Saito et al, 2000). This view has been supported by the identification, in several tumour types, of areas of 10q23 deletion distinct from PTEN (Singh et al, 1998a; Yeh et al, 1999). The relatively small number of loci analysed, and the absence of an intragenic marker in our study, raise the possibility that our findings of LOH were related to deletion of another gene at 10q23. However, the close proximity of D10S541 to PTEN $(<0.3 \mathrm{cM})$ and the higher incidence of D10S541 LOH in our study make it less likely that our findings are due to deletion of another tumour suppressor gene at this locus. Indeed, a high incidence of LOH at D10S541 was noted during fine structure deletion mapping of 10q22-24 in follicular thyroid adenomas and follicular thyroid carcinomas. In this study, LOH at D10S541 appeared to correlate with deletions of the PTEN gene (Yeh et al, 1999).

Other investigators have proposed that PTEN undergoes mechanisms of inactivation other than structural alteration, e.g. somatic mutation. An analysis of prostate cancer xenografts demonstrated decreased levels of both PTEN mRNA and PTEN protein in the absence of PTEN gene mutations (Whang et al, 1998). In this study, treatment with the demethylating agent 5azadeoxycytidine restored mRNA expression, suggesting that PTEN may undergo inactivation by promoter methylation. Similarly, an analysis of leukaemia and lymphoma cell lines demonstrated decreased levels of PTEN mRNA and PTEN protein, despite the fact that only a small minority of these samples contained PTEN mutations (Dahia et al, 1999). Interestingly, several additional cell lines in this study demonstrated decreased protein levels despite normal or high levels of
mRNA, suggesting that PTEN may be inactivated by both transcriptional silencing and by disruption at the protein level. Recently, multiple non-genetic mechanisms of PTEN inactivation have been observed in primary carcinomas of the thyroid, endometrium, cervix, and in melanomas (Gimm et al, 2000; Kurose et al, 2000; Mutter et al, 2000; Zhou et al, 2000).

Analyses of other tumour suppressor genes in oesophageal adenocarcinoma have demonstrated a similar high prevalence of $\mathrm{LOH}$ with a corresponding low rate of mutations. The p16 tumour suppressor gene, located on 9p21, encodes a cyclindependent kinase inhibitor. Allelic loss of 9p21 has been found in $26-89 \%$ of oesophageal adenocarcinomas; however, mutations in p16 are rare (Zhou et al, 1994; Gonzalez et al, 1997; Muzeau et al, 1997). Similarly, allelic loss of $5 \mathrm{q}$ has been reported in up to $75 \%$ of oesophageal adenocarcinomas, yet mutations of $A P C$ have been demonstrated in less than $10 \%$ of cases (Boynton et al, 1992; Zhuang et al, 1996; Gonzalez et al, 1997). Many of these tumour suppressor genes, like PTEN, may be regulated by mechanisms other than intragenic mutation. In the case of $p 16$, small homozygous microdeletions appear to be a major mechanism of inactivation, as does methylation of the $p 16$ promoter (Liggett and Sidransky, 1998). Loss of expression of p27, a cyclin-dependent kinase inhibitor, has also been demonstrated in a wide range of malignancies, including oesophageal adenocarcinoma (Esposito et al, 1997; Tan et al, 1997; Singh et al, 1998b; Yang et al, 1998). The expression of $p 27$ appears to be regulated by proteolytic degradation rather than by genetic mutation (Singh et al, 1998b).

LOH at 10q23 in our study did not correlate with any of the clinicopathologic features of the tumours analysed, nor did it correlate with overall survival. These findings contrast with those in breast cancer, where 10q23 LOH has been associated with adverse prognostic factors, including higher stage, higher tumour grade, and loss of oestrogen receptors (Bose et al, 1998; Garcia et al, 1999). In gliomas, the presence of PTEN mutations correlated with high tumour grade (Rasheed et al, 1997; Duerr et al, 1998; Davies et al, 1999; Zhou et al, 1999). However, among high-grade glioblastomas, in which the incidence of PTEN mutation is highest, PTEN mutations do not appear to influence overall survival (Zhou et al, 1999). Given that PTEN may undergo regulation through mechanisms other than somatic mutation, the level of PTEN expression in various malignancies may be a more useful prognostic marker than the presence of PTEN mutation. Indeed, in prostate cancer, loss of PTEN protein expression has been found to be associated with both a high Gleason score and advanced tumour stage, both markers of poor prognosis (McMenamin et al, 1999).

Of the other tumour suppressor genes lost or mutated in oesophageal adenocarcinoma, both $p 27$ and p53 have been analysed with regard to their effect on prognosis. Loss of p27 expression occurs in approximately $80 \%$ of BOAd, and is predictive of a poor prognosis (Singh et al, 1998b). Allelic loss of $17 \mathrm{p}$, the site of the $p 53$ oncogene, is common in oesophageal adenocarcinomas, and $p 53$ mutations have been demonstrated in approximately $50 \%$ of cases (Huang et al, 1992; Hamelin et al, 1994; Neshat et al, 1994; Gleeson et al, 1995; Hammoud et al, 1996; Schneider et al, 1996; Dolan et al, 1998). However, $p 53$ mutations do not have any prognostic significance in patients with these tumours (Flejou et al, 1994; Vijeyasingam et al, 1994).

In summary, we have demonstrated that, while LOH at 10q23 occurs in a subset of BOAd, intragenic mutations in the PTEN tumour suppressor gene do not play a significant role in the 
development of these lesions. Furthermore, LOH at 10q23 does not correlate with the major clinicopathologic features of these tumours. It is possible that PTEN activity is regulated by mechanisms other than intragenic mutation in BOAd.

\section{REFERENCES}

Alimov A, Li C, Gizatullin R, Fredriksson V, Sundelin B, Klein G and Zabarovsky E (1999) Somatic mutation and homozygous deletion of PTEN/MMAC1 gene at 10q23 in renal cell carcinoma. Anticancer Res 19: 3841-3846

Aveyard J, Skilleter A, Habuchi T and Knowles M (1999) Somatic mutations of PTEN in bladder carcinoma. Br J Cancer 80: 904-908

Blot W, Devesa S, Kneller R and Fraumeni J (1991) Rising incidence of adenocarcinoma of the esophagus and gastric cardia. JAMA $\mathbf{2 6 5}$ : $1287-1289$

Bose S, Wang S, Terry M, Hibshoosh H and Parsons R (1998) Allelic loss of chromosome 10q23 is associated with tumor progression in breast carcinomas. Oncogene 17: 123-127

Bostrom J, Cobbers J, Wolter M, Tabatabai G, Weber R, Lichter P, Collins V and Reifenberger G (1998) Mutation of the PTEN (MMAC1) tumor suppressor gene in a subset of glioblastomas but not in meningiomas with loss of chromosome arm 10q. Cancer Res 58: 29-33

Boynton R, Blount P, Yin J, Brown V, Huang Y, Tong Y, McDaniel T, Newkirk C, Resau J, Raskind W, Haggitt R, Reid B and Meltzer S (1992) Loss of heterozygosity involving the APC and MCC genetic loci occurs in the majority of human esophageal cancers. Proc Natl Acad Sci USA 89: 3385-3388

Butler M, Wang S, Chaganti R, Parsons R and Dalla-Favera R (1999) Analysis of PTEN mutations and deletions in B-cell non-hodgkins lymphomas. Genes Chromosomes Cancer 24: 322-327

Cairns P, Okami K, Halachmi S, Halachmi N, Esteller M, Herman J, Jen Isaacs W, Bova G and Sidransky D (1997) Frequent inactivation of PTEN/MMAC1 in primary prostate cancer. Cancer Res

Cairns P, Evron E, Okami K, Halamachi N, Esteller M, Herman J, Bose S, Wang S, Parsons R and Sidransky D (1998) Point mutation and homozygous deletion of PTEN/MMAC1 in primary bladder cancers. Oncogene 16: 3215-3218

Chen S, Yu S, Tsai M, Yeh K, Wang J, Kao M, Shih M and Chang J (1999) Mutation analysis of the putative tumor suppression gene PTEN/MMAC1 in sporadic breast cancer. Breast Cancer Res Treat 55: 85-89

Chiariello E, Roz L, Albarosa R, Magnani I and Finocchiaro G (1998) PTEN/MMAC1 mutations in primary glioblastomas and short-term cultures of malignant gliomas. Oncogene 16: 541-545

Dahia P, Marsh D, Zheng Z, Zedenius J, Komminoth P, Frisk T, Wallin G, Parsons R, Longy M, Larsson C and Eng C (1997) Somatic deletions and mutations in the Cowden disease gene, PTEN, in sporadic thyroid tumors. Cancer Res 57: $4710-4713$

Dahia P, Aguiar R, Alberta J, Kum J, Caron S, Sill H, Marsh D, Ritz J, Freedman A, Stiles C and Eng C (1999) PTEN is inversely correlated with the cell survival factor $\mathrm{Akt} / \mathrm{PKB}$ and is inactivated via multiple mechanisms in haematological malignancies. Hum Mol Genet 8: 185-193

Davies M, Gibbs F, Halliwell N, Joyce K, Roebuck M, Rossi M, Salisbury J, Sibson D, Tacconi L and Walker C (1999) Mutation in the PTEN/MMAC1 gene in archival low grade and high grade gliomas. Br J Cancer 79: 1542-1548

Dolan K, Grade J, Gosney J, Sissons M, Wright T, Kingsnorth A, Walker S, Sutton R, Meltzer S and Field J (1998) Allelotype analysis of oesophageal adenocarcinoma: loss of heterozygosity occurs at multiple sites. Br J Cancer 78: $950-957$

Dong J, Sipe T, Hyytinen E, Li C, Heise C, McClintlock D, Grant C, Chung L and Frierson H (1998) PTEN/MMAC1 is infrequently mutated in pT2 and pT3 carcinomas of the prostate. Oncogene 17: 1979-1982

Duerr E, Rollbrocker B, Hayashi Y, Peters N, Meyer-Puttlitz M, Louis D, Schramm J, Wiestler O, Parsons R, Eng C and Deimling A (1998) PTEN mutations in gliomas and glioneuronal tumors. Oncogene 16: 2259-2264

Esposito V, Baldi A, DeLuca A, Groger A, Loda M, Giordano G, Caputi M, Baldi F, Pagano M and Giordano A (1997) Prognostic role of the cyclin-dependent kinase inhibitor in non-small cell lung cancer. Cancer Res 57: 3381-3385

Feilotter H, Nagai M, Boag A, Eng C and Mulligan L (1998) Analysis of $\mathrm{PTEN}$ and the $10 \mathrm{q} 23$ region in primary prostate carcinomas. Oncogene 16: $1743-1748$

Feilotter H, Coulon V, McVeigh J, Goag A, Dorion-Bonnet F, Duboue B, Latham W, Eng C, Mulligan L and Longy M (1999) Analysis of the 10q23 chromosomal region and the PTEN gene in human sporadic breast carcinoma. $\mathrm{Br} J$ Cancer 79: $718-723$
Flejou J, Paraf F and Potet F (1994) p53 protein expression in Barrett's adenocarcinoma: a frequent event with no prognostic significance. Histopathology 24: 487-489

Fleming I, Cooper J and Henson D (1997) AJCC manual for staging of cancer, 5th ed. Berlin, New York: Wiley

Freihoff D, Kempe A, Beste B, Wappenschmidt B, Kreyer E, Hayashi Y, Meindl A, Krebs D, Wiestler O, Deimling A and Schmutzler R (1999) Exclusion of a major role for the PTEN tumour-suppressor gene in breast carcinomas. Br J Cancer 79: 754-758

Garcia J, Silva J, Dominguez G, Gonzalez R, Navarro A, Carretero L, Provencio M, Espana P and Bonilla F (1999) Allelic loss of the PTEN region (10q23) in breast carcinomas of poor pathophenotype. Breast Cancer Res Treat $\mathbf{5 7}$ : $237-243$

Gasparotto D, Vukosavljevic T, Piccinin S, Barzan L, Sulfaro S, Armellin M, Boiocchi M and Maestro R (1999) Loss of heterozygosity at 10q in tumors of the upper respiratory tract is associated with poor prognosis. Int J Cancer $\mathbf{8 4}$ : 432-436

Gimm O, Perren A, Weng L, Marsh D, Yeh J, Ziebold U, Gil E, Hinze R, Delbridge L, Lees J, Robinson B, Komminoth P, Dralle H and Eng C (2000) Differential nuclear and cytoplasmic expression of PTEN in normal thyroid tissue, and benign and malignant epithelial thyroid tumors. Am J Pathol 156: 1693-1700

Gleeson C, Sloan J and McGuigan J (1995) Base transitions at CpG nucleotides in the p53 gene are common in esophageal adenocarcinoma. Cancer Res 55: 3406-3411

Gonzalez M, Artimez M, Rodrigo L, Lopez-Larrea C, Menendez M, Alvarez V, Perez R, Fresno M, Perez M, Sampedro A and Coto E (1997) Mutation analysis of the p53, APC, and p16 genes in the Barrett's oesophagus, dysplasia, and adenocarcinoma. J Clin Pathol 50: 212-217

Gray I, Stewart L, Phillips S, Hamilton J, Gray N, Watson G, Spurr N and Snary D (1998) Mutation and expression analysis of the putative prostate tumoursuppressor gene PTEN. Br J Cancer 78: 1296-1300

Gronbaek Y, Zeuthen J, Guldberg P, Ralfkiaer E and Hou-Jensen K (1998) Alterations of the MMAC1/PTEN gene in lymphoid malignancies. Blood 91: 4388-4390

Guldberg P, Straten P, Birck A, Ahrenkiel V, Kirkin A and Zeuthen J (1997) Disruption of the MMAC1/PTEN gene by deletion or mutation is a frequent even in malignant melanoma. Cancer Res 57: 3660-3663

Hamelin R, Flejou J and Muzeau F (1994) TP53 gene mutations and p53 protein immunoreactivity in malignant and premalignant Barrett's esophagus. Gastroenterology 107: 1012-1018

Hammoud Z, Kaleem Z, Cooper J, Sundaresan R, Patterson G and Goodfellow P (1996) Allelotype analysis of esophageal adenocarcinomas: evidence for involvement of sequences on the long arm of chromosome 4. Cancer Res $\mathbf{5 6}$ : 4499-4502

Huang Y, Boynton R, Blount P, Silverstein R, Yin J, Tong Y, McDaniel T, Newkirk C, Resau J, Sridhara R, Reid B and Meltzer S (1992) Loss of heterozygosity involves multiple tumor suppressor genes in human esophageal cancers. Cancer Res 52: 6525-6530

Kohno T, Takahashi M, Manda R and Yokota J (1998) Inactivation of the PTEN/MMAC1/TEP1 gene in human lung cancers. Genes Chrom Cancer 22: $152-156$

Kong D, Suzuki A, Zou T, Sakurada A, Kemp L, Wakatsuki S, Yokoyama T, Yamakawa H, Furukawa T, Sato M, Ohuchi N, Sato S, Yin J, Wang S, Abraham J, Souza R, Smolinski K, Meltzer S and Horii A (1997) PTEN1 is frequently mutated in primary endometrial carcinomas. Nature Genet $\mathbf{1 7}$ : $143-144$

Kurose K, Zhou X, Araki T and Eng C (2000) Biallelic inactivating mutations and an occult germline mutation of PTEN in primary cervical carcinomas. Gene Chrom Cancer 29: 166-172

Lagergren J, Bergstrom R, Lindgren A and Nyren O (1999) Symptomatic gastroesophageal reflux as a risk factor for esophageal adenocarcinoma. NEngl J Med 340: 825-831

Li J, Yen C, Liaw D, Podsypanina K, Bose S, Wang S, Puc J, Miliaresis C, Rodgers L, MCombie R, Bigner S, Giovanella B, Ittman M, Tycko B, Hibshoosh H, Wigler M and Parsons R (1997) PTEN, a putative protein tyrosine phosphatase gene mutated in human brain, breast and prostate cancer. Science 275:

Liaw D, Marsh D, Li J, Dahia P, Wang S, Zheng Z, Bose S, Call K, Tsou H, Peacocke M, Eng C and Parsons R (1997) Germline mutations of the PTEN gene in Cowden disease, an inherited breast and thyroid cancer syndrome. Nat Genet 16: 64-67

Liggett W and Sidransky D (1998) Role of the p16 tumor suppressor gene in cancer. J Clin Oncol 16: 1197-1206 
Liu W, James D, Frederick L, Alderete B and Jenkins R (1997) PTEN/MMAC1 mutations and EGFR amplification in glioblastomas. Cancer Res 57: 5254-5257

Maier D, Zhang Z, Taylor E, Hamou M, Gratzl O, Meir E, Scott R and Merlo A (1998) Somatic deletion mapping on chromosome 10 and sequence analysis of PTEN/MMAC1 point to the 10q25-26 region as the primary target in lowgrade and high-grade gliomas. Oncogene 16: 5551-5555

Marsh D, Dahia P, Zheng Z, Liaw D, Parsons R, Gorlin R and Eng C (1997a) Germline mutations in PTEN are present in Bannayan-Zonana syndrome. Nature Genet 16: 333-334

Marsh D, Roth S, Lunetta K, Hemminki A, Dahia P, Sistonen P, Zheng Z, Caron S, Orsouw N.v, Bodmer W, Cottrell S, Dunlop M, Eccles D, Hodgson S, Jarvinen H, Kellokumpu I, Markie D, Neale K, Phillips R, Rozen P, Syngal S, Vijg J, Tomlinson I, Aaltonen L and Eng C (1997b) Exclusion of PTEN and 10q22-24 as the susceptibility locus for juvenile polyposis syndrome. Cancer Res $\mathbf{5 7}$ 5017-5021

Marsh D, Dahia P, Caron S, Kum J, Fralyling I, Tomlinson I, Hughes K, Eeles R, Hodgson S, Murday V, Houlston R and Eng C (1998) Germline PTEN mutations in Cowden syndrome-like families. J Med Genet 35: 881-885

Marsh D, Kum J, Lunetta K, Bennett M, Gorlin R, Ahmed S, Bodurtha J, Crowe C, Curtis M, Dasouki M, Dunn T, Feit H, Geraghty M, Graham J, Hodgson S, Hunter A, Korf B, Manchester D, Miesfeldt S, Murday V, Nathanson K, Paris M, Pober B, Romano C, Tolmie J, Trembath R, Winter R, Zackai E, Zori R, Weng L, Dahia P and Eng C (1999) PTEN mutation spectrum and genotypephenotype correlations in Bannayan-Riley-Ruvalcaba syndrome suggest a single entity with Cowden syndrome. Hum Molec Genet 8: 1461-1472

McMenamin M, Soung P, Perera S, Kaplan I, Loda M and Sellers W (1999) Loss of PTEN expression in paraffin-embedded primary prostate cancer correlates with high Gleason score and advanced stage. Cancer Res 59: 4291-4296

Mutter G, Lin M, Fitzgerald J, Kurn J, Baak J, Lees J, Weng L and Eng C (2000) Altered PTEN expression as a diagnostic marker for the earliest endometrial precancers. J Natl Cancer Inst 92: 924-931

Muzeau F, Flejou J, Thomas T and Hamelin R (1997) Loss of heterozygosity on chromosome 9 and p16 (MTS1, CDKN2) gene mutations in esophageal cancers. Int J Cancer 72: 27-30

Myers M, Stolarov J, Eng C, Li J, Wang S, Wigler M, Parsons R and Tonks N (1997) PTEN, the tumor suppressor from human chromosome 10q23, is a dual specificity phosphatase. Proc Natl Acad Sci (USA) 94: 9052-9057

Nakahara Y, Nagai H, Kinoshita T, Uchida T, Hatano S, Murate T and Saito H (1998) Mutational analysis of the PTEN/MMAC1 gene in non-hodgkin's lymphoma. Leukemia 12: 1277-1280

Neshat K, Sanchez C and Galipeau P (1994) p53 mutations in Barrett's adenocarcinoma and high grade dysplasia. Gastroenterology 106: 1589-1595

Obata K, Morland S, Watson R, Hitchcock A, Chenevix-Trench G, Thomas E and Campbell I (1998) Frequent PTEN/MMAC mutations in endometrioid but not serous or mucinous epithelial ovarian tumors. Cancer Res 2095-2097

Okami K, Wu L, Riggins G, Cairns P, Goggins M, Evron E, Halachmi N, Ahrendt S, Reed A, Hilgers W, Kern S, Koch W, Sidransky D and Jen J (1998) Analysis of PTEN/MMAC1 alterations in aerodigestive tract tumors. Cancer Res 509-511

Pesche S, Latil A, Muzeau F, Cussenot O, Fournier G, Longy M, Eng C and Lidereau R (1998) PTEN/MMAC1/TEP1 involvement in primary prostate cancers. Oncogene 16: 2879-2883

Petersen S, Rudolf J, Bockmuhl U, Gellert K, Wolf G, Dietel M and Petersen I (1998) Distinct regions of allelic imbalance on chromosome 10q22-q26 in squamous cell carcinomas of the lung

Rasheed B, Stenzel T, McLendon R, Parsons R, Friedman A, Friedman H, Bigner D and Bigner S (1997) PTEN gene mutations are seen in high grade but not in low grade gliomas. Cancer Res 57: 4187-4190

Risinger J, Hayes A, Berchuk A and Barrett J (1997) PTEN/MMAC1 mutations in endometrial cancers. Cancer Res 57: 4736-4738

Saito M, Okamoto A, Kohno T, Takakura S, Shinozaki H, Isonishi S, Yasuhara T, Yoshimura T, Ohtake Y, Ochiai K, Yokota J and Tanaka T (2000) Allelic imbalance and mutations of the PTEN gene in ovarian cancer. Int J Cancer $\mathbf{8 5}$ $160-165$

Sakai A, Thieblemont C, Wellmann A, Jaffe E and Raffeld M (1998) PTEN gene alterations in lymphoid neoplasms. Blood 92: 3410-3415

Schneider P, Casson A, Levin B, Garewal H, Hoelscher A, Becker K, Dittler H, Cleary K, Troster M, Siewert J and Roth J (1996) Mutations of p53 in Barrett's esophagus and Barrett's cancer: a prospective study of ninety-eight cases. $J$ Thorac Cardiovasc Surg 111: 323-333

Shao X, Tandon R, Samara G, Kanki H, Yano H, Close L, Parsons R and Sato T (1998) Mutational analysis of the PTEN gene in head and neck squamous cell carcinoma. Int $J$ Cancer 77: 684-688
Simpkins S, Peiffer-Schneider S, Mutch D, Gersell D and Goodfellow P (1998) PTEN mutations in endometrial cancers with 10q LOH: additional evidence for the involvement of multiple tumor suppressors. Gynecol Oncol 71: 391-395

Singh B, Ittmann M and Krolewski J (1998a) Sporadic breast cancers exhibit loss of heterozygosity on chromosome segment 10q23 close to the Cowden disease locus. Genes Chromosomes Cancer 21: 166-171

Singh S, Lipman J, Goldman H, Ellis F, Aizenman L, Cangi M, Signoretti S, Chiaur D, Pagano M and Loda M (1998b) Loss or altered subcellular localization of p27 in Barrett's associated adenocarcinoma. Cancer Res 58: 1730-1735

Steck P, Pershouse M, Jasser S, Yung W, Lin H, Ligon A, Langford L, Baumgard M, Hattier T, Davis T, Frye C, Hu R, Swedlund B, Teng D and Tavtigian S (1997) Identification of a candidate tumor suppressor gene, MMAC1, at chromosome $10 \mathrm{q} 23.3$ that is mutated in multiple advanced cancers. Nature Genet $\mathbf{1 5}$ : 356-362

Suzuki H, Freije D, Nusskern D, Okami K, Cairns P, Sidransky D, Isaacs W and bova G (1998) Interfocal heterogeneity of PTEN/MMAC1 gene alterations in multiple metastatic prostate cancer tissues. Cancer Res 58: 204-209

Tan P, Cady B, Wanner M, Worland P, Cukor B, Magi-Galluzzi C, Lavin P, Draetta G, Pagano M and Loda M (1997) The cell cycle inhibitor p27 is an independent prognostic marker in small (T1a, b) invasive breast carcinomas. Cancer Res $\mathbf{5 7}$ $1259-1263$

Tashiro H, Blazes M, Wu R, Cho K, Bose S, Wang S, Li J, Parsons R and Ellenson L (1997) Mutations in PTEN are frequent in endometrial carcinoma but rare in other common gynecological malignancies. Cancer Res 57: 3935-3940

Teng D, Hu R, Lin H, Davis T, Iliev D, Frye C, Swedlund B, Hansen K, Vinson V, Gumpper K, Ellis L, El-Naggar A, Frazier M, Jasser S, Langford L, Lee J, Mills G, Pershouse M, Pollack R, Tornos C, Troncoso P, Yung W, Fujii G, Berson A, Bookstein R, Bolen J, Tavtigian S and Steck P (1997) MMAC1/PTEN mutations in primary tumor specimens and cell lines. Cancer Res 57: 5221-5225

Tsao H, Zhang X, Benoit E and Haluska F (1998) Identification of PTEN/MMAC1 alterations in uncultured melanomas and melanoma cell lines. Oncogene $\mathbf{1 6}$ $3397-3402$

Vijeyasingam R, Darnton S, Jenner K, Allen C, Billingham C and Matthews H (1994) Expression of p53 protein in oesophageal carcinoma: clinicopathological correlation and prognostic significance. Br J Surg $\mathbf{8 1}$ $1623-1626$

Wang S, Puc J, Li J, Bruce J, Cairns P, Sidransky D and Parsons R (1997) Somatic mutations of PTEN in glioblastoma multiforme. Cancer Res 57: $4183-4186$

Whang Y, Wu X, Suzuki H, Reiter R, Tran C, Vessalla R, Said J, Isaacs W and Sawyers C (1998) Inactivation of the tumor suppressor PTEN/MMAC1 in advanced human prostate cancer through loss of expression. PNAS 95 : $5246-5250$

Yaginuma Y, Yamashita T, Ishiya T, Morizaki A, Katoh Y, Takahashi T, Hayashi H and Ishikawa M (2000) Abnormal structure and expression of PTEN/MMAC1 gene in human uterine cancers. Molecular Caricinogenesis 27: $110-116$

Yang R, Naitoh J, Murphy M, Wang H, Phillipson J, deKernion J, Loda M and Reiter R (1998) Low p27 expression predicts poor disease-free survival in patients with prostate cancer. J Urol 159: 941-945

Yeh J, Marsh D, Zedenius J, Dwight T, Delbridge L, Robinson B and Eng C (1999) Fine-structure deletion mapping of 10q22-24 identifies regions of loss of heterozygosity and suggests that sporadic follicular thyroid adenomas and follicular thyroid carcinomas develop along distinct neoplastic pathways. Genes Chromosomes Cancer

Yokomizo A, Tindall D, Drabkin H, Gemmill R, Franklin W, Yang P, Sugio K, Smith D and Liu W (1998) PTEN/MMAC1 mutations identified in small cell, but not in non-small cell lung cancers. Oncogene 17: 475-479

Zhou X, Tarmin L, Yin J, Jiang H, Suzuki H, Rhyu M, Abraham J and Meltzer S (1994) The MTS1 gene is frequently mutated in primary human esophagea tumors. Oncogene 9: 3737-3741

Zhou X, Li Y, Hoang-Xuan K, Laurent-Puig P, Mokhtari K, Longy M, Sanson M, Delattre J, Thomas G and Hamelin R (1999) Mutational analysis of the PTEN gene in gliomas: molecular and pathological correlations. Int $J$ Cancer $\mathbf{8 4}$ : $150-154$

Zhou X, Gimm O, Hampel H, Niemann T, Walker M and Eng C (2000) Epigenetic PTEN silencing in malignant melanomas without PTEN mutation. Am J Pathol 157: $1123-1128$

Zhuang Z, Vortmeyer A, Mark E, Odze R, Emmert-Buck M, Merino M, Moon H, Liotta L and Duray P (1996) Barrett's esophagus: metaplastic cells with loss of heterozygosity at the APC gene locus are clonal precursors to invasive adenocarcinoma. Cancer Res 56: 1961-1964 